\title{
Comparison between Taq DNA Polymerase and Its Stoffel Fragment for Quantitative Real-Time PCR with Hybridization Probes
}

BioTechniques 30:1052-1062 (May 2001)

\author{
Jochen Wilhelm, Alfred \\ Pingoud, and Meinhard Hahn \\ Justus-Liebig-Universität \\ Giessen, Germany
}

\begin{abstract}
In quantitative real-time PCR assays, fluorophor-labeled oligonucleotide probes are employed to generate sequence-specific signals for the quantitative evaluation. Whereas TaqMan ${ }^{\circledR}$ probes have to be hydrolyzed during PCR by the endonucleolytic activity of Taq DNA polymerase to generate a signal, the hybridization probes in LightCycler ${ }^{\circledR}$ assays must not be hydrolyzed. In this study, we demonstrate for four different targets that the probes are degraded during PCR by Taq DNA polymerase. Signal yield, quality of amplification curves, and accuracy of quantitative measurements can be im proved using the Stoffel fragment lacking an endonucleolytic activity and TaqStart ${ }^{\circledR}$ antibody suppressing the formation of nonspecific products, without laborious efforts to optimize the amplification protocol.
\end{abstract}

\section{INTRODUCTION}

Real-time quantitative PCR is becoming an increasingly important method for determining copy numbers of nucleic acid sequences $(1,2,7)$. For sequence-specific signal generation, fluorescent probes are usually employed that change their fluorescence intensity when they bind to the amplified DNA. Therefore, the fluorescence signal, measured once per cycle, will increase with the product accumulation during the PCR. The change in fluorescence intensity is either due to a loss of fluorescence quench [e.g., TaqMan ${ }^{\circledR}$ probes (4) or Molecular Beacons ${ }^{\mathrm{TM}}$ (6)] or due to a gain of fluorescence resonance energy transfer (FRET) from a donor to an acceptor fluorophor [hybridization probes format (9)]. For signal generation, the double-labeled TaqMan probes have to be hydrolyzed by the endonucleolytic activity of the Taq DNA polymerase to unlink the quencher and the fluorophor. Initially, Taq DNA polymerase partially removes hybridized oligonucleotides on the template strand, obstructing the passage for polymerization, forming a Yshaped DNA structure. Then, the unpaired 5'-arm of the bifurcated duplex is removed by the structure-specific endonuclease activity of the Taq DNA polymerase (5). In contrast, the singlelabeled oligonucleotides of the hybridization probe pairs have to be reused in each PCR cycle and, therefore, should not be hydrolyzed to avoid a decrease of the effective probe concentration. There are no data in the literature that would demonstrate whether and to what extent probe hydrolysis in- terferes with quantification using the LightCycler ${ }^{\circledR}$ system (Roche Diagnostics, Penzberg, Germany).

Here, we demonstrate on four different targets that hybridization probes are hydrolyzed endonucleolytically by this Taq endonuclease activity. The signal yield might be reduced because of the successively reduced amount of intact probes. Therefore, the signal-to-noise ratio becomes smaller, which finally may affect accuracy and sensitivity. These potential disadvantages in LightCycler (8) quantitative PCR assays, employing hybridization probes, can be avoided using the Stoffel fragment of Taq DNA polymerase (3) lacking endonucleolytic activity.

\section{MATERIALS AND METHODS}

\section{DNA Isolation}

Human genomic RNA-free DNA was isolated from lymphocytes of fresh EDTA-treated blood using the QIA amp $^{\circledR}$ DNA Blood Kit (Qiagen, Hilden, Germany) following the manufacturer's instructions. DNA quality and concentration were evaluated by absorption spectroscopy between 220 and $320 \mathrm{~nm}$ using a Hitachi U-3000 spectrophotometer (Hitachi, Tokyo, Japan).

\section{Oligonucleotides}

Primers $\left(\mathrm{HPSF}^{\circledR}\right.$-purified; MWG, Ebersberg, Germany) and hybridization probes (TIB Molbiol, Berlin, Germany) (Table 1) were checked with the program Oligo ${ }^{\circledR} \quad 5.0$ (National Biosciences, Plymouth, MN, USA) for the 
Table 1. Oligonucleotides Used in This Study

\begin{tabular}{|c|c|c|c|}
\hline Target & Name & Sequence $\left(5^{\prime} \rightarrow 3^{\prime}\right)$ & Genome Localizationa \\
\hline p53 & p53-Fb & TTCCTAGCACTGCCCAACA & 14674-14692 \\
\hline$p 53$ & p53-R & GACTGGAAACTTTCCACTTG & $14779-14798$ \\
\hline$p 53$ & p53-up & CCCCAGCCAAAGAAGAAACCACTGGATGGAGAAT-FAMC & $14707-14740$ \\
\hline p53 & p53-down & Red640-TTTCACCCTTCAGGTACTAAGTCTTGGGACCTCTT-p & $14742-14776$ \\
\hline p16 & $\mathrm{p} 16-\mathrm{F}$ & AAGCCATTGCGAGAACTT & $146-163$ \\
\hline p16 & $\mathrm{p} 16-\mathrm{R}$ & CAGAGGGCAGAAAGAAAA & $253-270$ \\
\hline p16 & p16-up & CGGTAGGGACGGCAAGAGAGGAGGGCGGGA-FAM & $185-214$ \\
\hline p16 & p16-down & Red640-TGTGCCACACATCTTTGACCTCAGGTTTCTAACG-p & $215-248$ \\
\hline IGF-1 & igf- $\mathrm{F}$ & AGCTCGGCATAGTCTT & $1135-1150$ \\
\hline IGF-1 & igf-R & CCAAGTGAGGGGTGTGA & $1241-1257$ \\
\hline IGF-1 & igf-up & ATGAGACAGTGCCCTAAAGGGACCAATCCAATG-FAM & $1174-1206$ \\
\hline IGF-1 & igf-Down & Red640-CTGCCTGCCCCTCCATAGGTTCTAGGAAATGAG-p & $1207-1239$ \\
\hline$H B B$ & hbb-F & ACACAACTGTGTTCACTAGC & $143-162$ \\
\hline$H B B$ & hbb-R & СААСTTCATCCACGTTCACC & $233-252$ \\
\hline$H B B$ & hbb-up & CAAACAGACACCATGGTGCACCTGACTCCTGAGGA-FAM & 168-202 \\
\hline HBB & hbb-down & Red640-GAAGTCTGCCGTTACTGCCCTGTGGGGCAA-p & 203-232 \\
\hline \multicolumn{4}{|c|}{$\begin{array}{l}\text { aNucleotide positions are based on sequence of the human genes TP53 (GenBank }{ }^{\circledR} \text { accession no. X54156), p16 (INK4A } \\
\text { (GenBank accession no. U12820), IGF-1 (GenBank accession no. M12659), HBB (Homo sapiens } \beta \text {-globin gene) (GenBank } \\
\text { accession no. AF007546). } \\
\text { bF, foreward primer; R, reverse primer; up, donor probe; down, acceptor probe. } \\
\text { 'FAM, 5,6-carboxyfluorescein attached to } 3 \text { '-O-ribose; Red640, LightCycler Red } 640 \text { attached to } 5^{\prime} \text { terminus; p, phosphate } \\
\text { group attached to the } 3^{\prime} \text { terminus. }\end{array}$} \\
\hline
\end{tabular}

absence of false priming sites, formation of primer dimers, primer/probe hybrids, and secondary structures. The probe pairs hybridize between the primer binding sites such that donor (fluorescein) and acceptor (Red 640) fluorophor are in sufficient proximity for an efficient FRET process.

\section{Real-Time PCR}

A LightCycler system (Roche Diagnostics) was used for amplification and data collection (software version 3 ). Reactions were carried out in a total volume of $10 \mu \mathrm{L}$ per capillary. Each reaction mixture contained $0.5 \mathrm{mg} / \mathrm{mL}$ BSA, $6 \mathrm{mM} \mathrm{MgCl}_{2}, 0.5 \mu \mathrm{M}$ each primer, $0.2 \mu \mathrm{M}$ each probe, $0.2 \mathrm{mM}$ dATP, dCTP, dGTP, and dTTP, 0.5 U Taq DNA polymerase (Roche Diagnostics) or 0.5 U Stoffel fragment (Applied Biosystems, Weiterstadt, Germany), and $15 \mathrm{ng}$ (unless otherwise stated) hu- man genomic template DNA in $1 \times$ PCR buffer (for Taq DNA polymerase: 10 $\mathrm{mM}$ Tris- $\mathrm{HCl}, \mathrm{pH} \mathrm{8.3,50} \mathrm{mM} \mathrm{KCl}$; for Stoffel fragment: $10 \mathrm{mM}$ Tris- $\mathrm{HCl}, \mathrm{pH}$ $8.3,10 \mathrm{mM} \mathrm{KCl}$ ). All other biochemicals were from Roche Diagnostics. The reaction conditions were optimized to obtain the highest signal-to-noise ratio.

The reaction mixture, produced at $4^{\circ} \mathrm{C}$ to prevent the formation of nonspecific products, was distributed into prechilled capillaries. For reactions containing TaqStart ${ }^{\circledR}$ antibody (Clontech Laboratories, Heidelberg, Germany), DNA polymerase and antibody were premixed (molar ratio 1:28) in TaqStart dilution buffer $(50 \mathrm{mM} \mathrm{KCl}, 10 \mathrm{mM}$ Tris- $\mathrm{HCl}, \mathrm{pH} 7.0$ ) and incubated for 5 min at room temperature.

For analysis of the kinetics of probe hydrolysis during PCR, the 6-fold amount of reaction mixture was prepared for each target and kept on ice. Five reactions with an increasing num- ber of amplification cycles $(0,20,30$, 40 , and 50 cycles) were carried out sequentially.

Each target was amplified in four different assays: either with Taq DNA polymerase or Stoffel fragment, in the presence or absence of TaqStart antibody. To determine the reproducibility of quantifications, these four assays were carried out two times in quadruplicate. The threshold value was adjusted separately for each set of quadruplicate measurements to minimize the standard deviation of the resulting $\mathrm{C}_{\mathrm{T}}$ values.

\section{Amplification Protocol}

Initial denaturation for $30 \mathrm{~s}$ at $95^{\circ} \mathrm{C}$ was followed by $20-50$ amplification cycles with $0 \mathrm{~s}$ at $95^{\circ} \mathrm{C}, 5 \mathrm{~s}$ at $55^{\circ} \mathrm{C}$, and $10 \mathrm{~s}$ at $72^{\circ} \mathrm{C}$ (temperature ramp always $20^{\circ} \mathrm{C} / \mathrm{s}$ ). The measurement was done at the end of the annealing phase at $55^{\circ} \mathrm{C}$. The PCR raw data were evaluated with 
the LightCycler software, version 3. The signal of channel 2 and the ratio channel 2:channel 1 were used to calculate the $\mathrm{C}_{\mathrm{T}}$ values (fit points method using three points per curve within the detected exponential phase of amplification; arithmetric baseline adjustment).

\section{Analysis of the Donor Probes by Capillary Electrophoresis}

The FAM-labeled donor probes were quantitatively analyzed for hydrolysis by capillary electrophoresis using an ABI PRISM ${ }^{\mathrm{TM}} 310$ Genetic Analyzer (instrument, reagents, and consumables from Applied Biosystems). Immediately after PCR, each reaction mixture was 10 -fold diluted with water. Two microliters of each dilution were mixed with $12 \mu \mathrm{L}$ template suppression reagent, heated for $3 \mathrm{~min}$ at $95^{\circ} \mathrm{C}$, and instantaneously chilled on ice.

These samples were injected electrokinetically for $5 \mathrm{~s}$ at $15 \mathrm{kV}$ and separated at $15 \mathrm{kV}$ and $60^{\circ} \mathrm{C}$ in a $47 \mathrm{~cm} \times$ $50 \mu \mathrm{m}$ capillary of uncoated fused silica filled with polymer POP4 using the module "GS STR POP4 (1 mL) C". Laser-induced fluorescence signals were recorded by the collection software version 1.0.4 and evaluated with the GeneScan ${ }^{\circledR}$ software, version 2.1 (Applied Biosystems).

The fraction of hydrolyzed probes $\mathrm{p}$ was calculated using Equation 1:

$$
p=\frac{A_{H}}{A_{T}}-\frac{A_{H_{\mathrm{O}}}}{A_{T_{\mathrm{O}}}}
$$

with $A_{H}$ : sum of peak areas corresponding to hydrolyzed donor probes; $\mathrm{A}_{\mathrm{T}}$ : sum of all peak areas of the donor probe; $A_{\mathrm{Ho}}: A_{\mathrm{H}}$ before PCR; $A_{\mathrm{To}}: A_{\mathrm{T}}$ before PCR. The ratio $A_{\mathrm{Ho}} / \mathrm{A}_{\mathrm{To}}$ corresponds to the initial fraction of nonfull-length donor probe, which is determined from an aliquot of the pre-PCR reaction mixture. The error of these calculations is approximately $2 \%$.

\section{RESULTS}

We studied the influence of the endonucleolytic activity of Taq DNA polymerase on the sensitivity and accuracy in quantitative PCR experiments using the LightCycler employing hybridization probes. Our goal was to determine the optimum conditions for very precise gene copy number quantification, as it is required for the detection of oncogene amplifications or tumor suppressor gene deletions in clinical samples.

Quantifications of the $I G F-1$ copy number in a sample containing $15 \mathrm{ng}$ human genomic DNA were carried out with Taq DNA polymerase or its Stoffel fragment (3). The Stoffel fragment showed several nonspecific amplification products (data not shown), which were not formed when TaqStart antibody was added. Figure 1 shows the cycle-dependent signal for the external standards used for these quantifications. Generally, the fluorescence signals of the PCRs carried out with Stoffel fragment (Figure 1, c and d) reach higher values than those using Taq DNA polymerase (Figure 1, a and $b$ ) (in the example presented, approximately 2.5 -fold higher intensity). Because of the higher signal intensities in the case of the Stoffel fragment, the signal-to-noise ratio of these curves is lower and the curves appear to be smoother in shape (similar results were found for amplifications of $p 16, p 53$, and $H B B$ (human $\beta$-globin gene), data not shown). In addition, the curves of the standards are more parallel and equidistant. Therefore, the error of the standard curves obtained is lower, which is indicative of a higher accuracy. The lowest error of standard curves, and therefore the highest accuracy, is obtained with the combination of Stoffel fragment plus antibody (Figure 1d). This is confirmed by the lower standard deviations of the $\mathrm{C}_{\mathrm{T}}$ values of measurements carried out in quadruplicate. The mean standard deviations of the $\mathrm{C}_{\mathrm{T}}$ values were approximately $30 \%$ smaller when Stoffel fragment was used instead of Taq DNA polymerase (mean SD over all targets: Taq DNA polymerase: 0.11; Stoffel fragment: 0.07). The reproducibility of the measurements is always better if the ratio of the acceptor and donor fluorescence is used for evaluation rather than the acceptor fluorecence only: the SD of the measurements is 2-3 times higher when the acceptor fluorescence value only is used for evaluation (Taq DNA polymerase: $\overline{\mathrm{S}} \mathrm{D}=$ 0.27; Stoffel fragment: $\overline{\mathrm{S}} \overline{\mathrm{D}}=0.17$ ).
To verify whether the better suitability of the Stoffel fragment for precise quantifications is due to the absence of probe hydrolysis, we analyzed the probes and their degradation products by ABI PRISM 310 capillary electrophoresis (CE) (Figure 2). Because this CE system uses an argon ion laser for excitation, only the fluorescein of the donor probes is excited, while the Red 640-labeled acceptor probes cannot be detected. Unhydrolyzed probes show two peaks in the electropherograms corresponding to the isomers 5and 6-carboxy-fluorescein, which exhibit a slightly different mobility. As shown for IGF-1 (Figure 2a), there is no change in the electropherogram even after 50 cycles of amplification when the Stoffel fragment is used. In contrast, the amount of shorter fragments is increased after 50 cycles when using Taq DNA polymerase, as demonstrated for $I G F-1$ (Figure 2b), p16 (Figure 2c), p53, and $H B B$ (data not shown). The probes are not sequentially degraded but hydrolyzed at certain preferred internal positions, mostly around 10 nucleotides away from the 5 -end (cf. Figure 2).

Because the situation after 50 PCR cycles (very late plateau phase) does not reflect the situation during the exponential phase that is used for evaluation of real-time quantifications, we also analyzed the cycle-dependent degradation of probes: after every 10 cycles, one reaction of a series of identical PCRs was stopped and analyzed by CE. The fraction of hydrolyzed probes increases with the amplification signal (Figure 3): at the end of the time segment, used for calculation of the $\mathrm{C}_{\mathrm{T}}$ values, up to approximately $15 \%$ of the donor probes are degraded (e.g., $H B B$ and p16). The amount of donor probe hydrolysis for the various targets is given in Table 2.

It may be argued that, by lowering the $\mathrm{Mg}^{2+}$ concentration in the reaction, the amount of probe hydrolysis by Taq DNA polymerase could be effectively decreased. This is indeed the case but only to a minor degree (Table 2) and accompanied by a substantial loss and decrease in quality of the signal (Figure 4a). The Stoffel fragment does not appear to hydrolyze the probe at any $\mathrm{Mg}^{2+}$ concentration tested; however, 


\section{Research Report}

Table 2. Dependence of Donor Probe Hydrolysis on $\mathrm{Mg}^{2+}$ Concentration

\begin{tabular}{|lcccc|}
\hline & \multicolumn{4}{c|}{ Degradation after 30/50 cycles [\%] } \\
\cline { 2 - 5 } Mg $^{2+}$ & HBB & IGF-1 & p53 & p16 \\
\hline $3 \mathrm{mM}$ & $8 / 21$ & $<1 / 10$ & $12 / 27$ & $3 / 24$ \\
$4 \mathrm{mM}$ & $26 / 78$ & $7 / 19$ & $12 / 32$ & $6 / 41$ \\
$5 \mathrm{mM}$ & $31 / 44$ & $3 / 12$ & $12 / 55$ & $10 / 32$ \\
$6 \mathrm{mMa}$ & $23 \pm 8 / 39 \pm 18$ & $3 \pm 2 / 14 \pm 9$ & $13 \pm 6 / 40 \pm 11$ & $10 \pm 4 / 39 \pm 1$ \\
aThese experiments were carried out in duplicate. & \\
\hline
\end{tabular}

only at $6 \mathrm{mM} \mathrm{Mg}^{2+}$ is a useful signal obtained (Figure 4b).

\section{DISCUSSION}

The Taq DNA polymerase, commonly used for real-time quantitative PCR assays $(1,2,7,8)$, has two different enzymatic activities: the DNA polymerase activity, localized in the C-terminal domain, and a structure-specific endonuclease activity in the N-terminal domain $(3,5)$. Whereas the double-labeled TaqMan probes have to be hy- a)

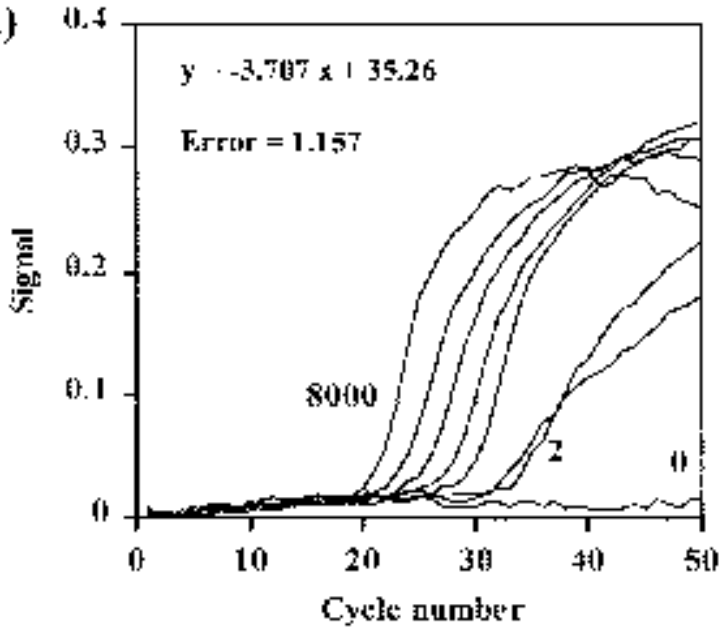

c)

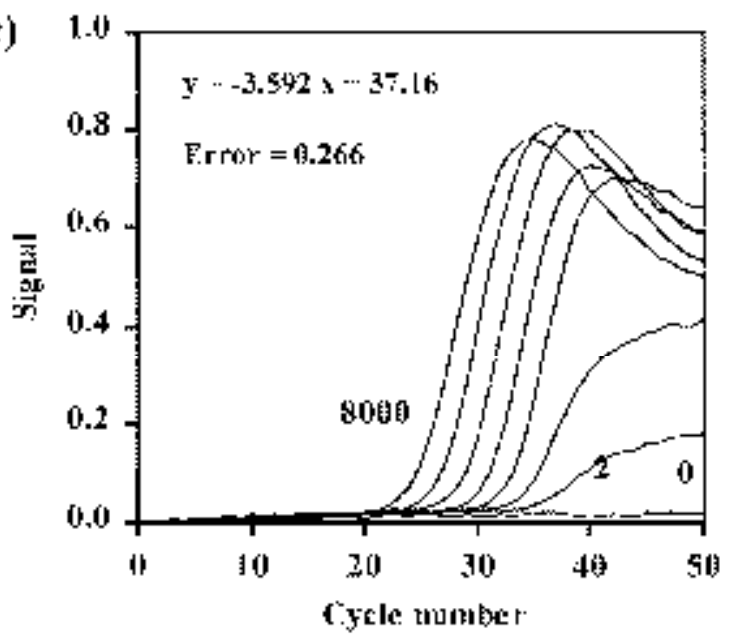

h)
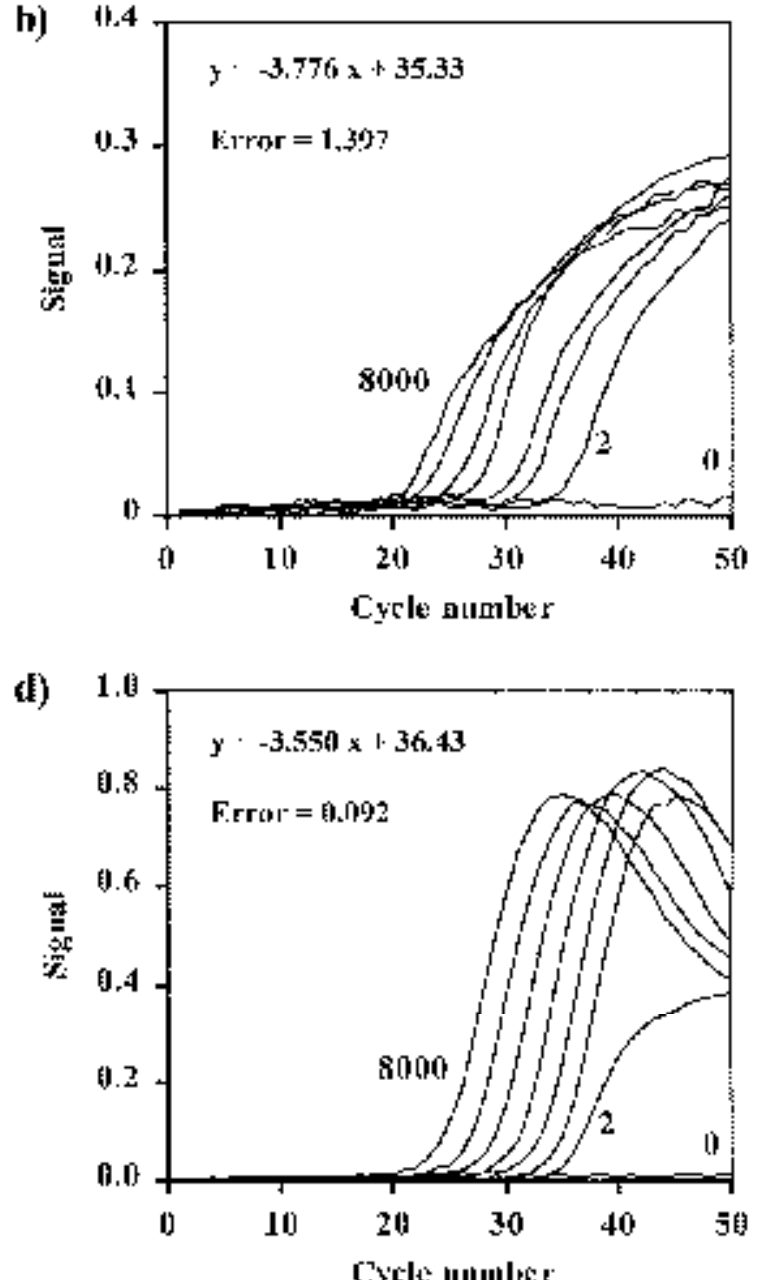

C? yctel multe:

Figure 1. IGF-1 amplification profiles of a dilution series of human genomic DNA. The DNA was diluted with water in steps of 1:4 from 8000 down to approximately 2 genomic equivalents ( 3 ng were assumed to be 1000 haploide genome equivalents). The negative control without DNA is indicated by " 0 ". Am plifications were done with (a) Taq DNA polymerase, (b) Taq DNA polymerase and TaqStart antibody, (c) Taq Stoffel fragment, and (d) Taq Stoffel fragment and TaqStart antibody. The standard curve, obtained by plotting log copy number versus $\mathrm{G}$ and given in the form $\mathrm{y}=\mathrm{ax}+\mathrm{b}$, was calculated using the fit points method with arithmetic background correction. The error value of the standard curve is the error calculated by the LightCycler software; the coefficient of correlation was greater than 0.98 in all cases. 

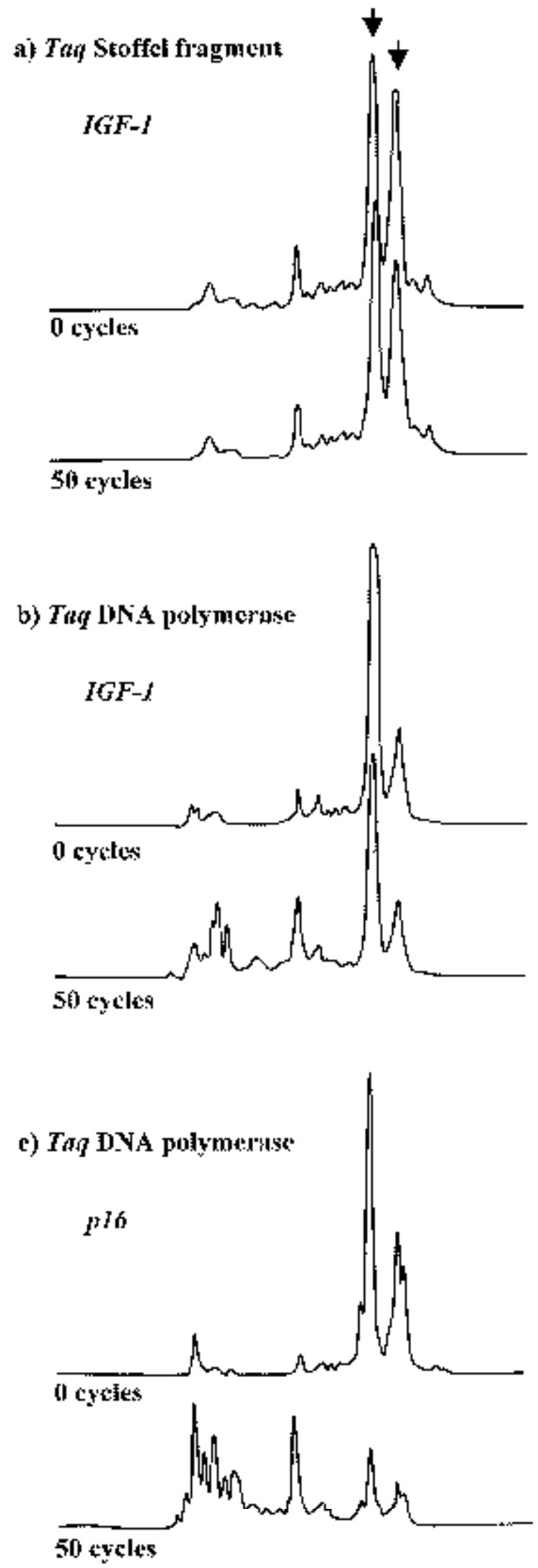

drolyzed for the generation of fluorescence signal by the nucleolytic activity of the Taq DNA polymerase (1), ideally, the single-labeled hybridization probes used for LightCycler PCRs must not be hydrolyzed to avoid a decrease of the effective probe concentration during the PCR.

In a LightCycler PCR, Taq DNA polymerase leads to probe hydrolysis, the extent to which this occurs is dependent on the sequence of the probe and on the concentration of $\mathrm{Mg}^{2}+$ ions (Table $2)$. The hybridization probes are degraded by the endonucleolytic activity of the Taq DNA polymerase (5). This was shown by the capillary electrophoretic analysis of the PCR mixtures. Fresh preparations of hybridization probes already contain shorter products (Figure 2 ) caused by incomplete synthesis. The amount of shorter products increases during PCR, when Taq DNA polymerase is used but not when Stoffel fragment is used. This proves that the accumulation of degraded probes is specifically due to the endonucleolytic activity of the Taq DNA polymerase. The degradation of the probes is nonsequential because the relative proportions of individual hydrolyzed probe fragments remain constant during the PCR. The Taq DNA polymerase mainly cleaves the donor probes around 5 and 12 nucleotides from their $5^{\prime}$-terminus as shown by Lyamichev et al. (5). The exponential phase of product accumulation of the PCR is used for the evaluation of quantifications. During this phase, up to approximately $15 \%$ of the probes are degraded. The amount depends not only on the sequence. Even in identical reactions, the amounts of degraded probes,

Figure 2. Hydrolysis of donor probes analyzed by denaturing capillary electrophoresis. Aliquots of the reaction mixture before PCR $(0$ cycles) and after 50 amplification cycles are com pared. The two peaks indicated by arrows correspond to the non-hydrolyzed probes with the isomers 5- and 6-carboxy-fluorescein. The peaks left from the full-length probes correspond to degraded probes labeled with fluorescein. (a) igf-up probe before and after PCR with Taq Stoffel fragment, (b) like (a) with Taq DNA polymerase, (c) p16-up probe before and after PCR with Taq DNA polymerase. The lengths of the non-hydrolyzed probes are 33 (igf-up) and 30 nucleotides (p16up). The traces shown correspond to the separation time between 10 and 12 min after injection. 


\section{Research Report}

accumulated within the exponential phase, differ by $\pm 10 \%$, perhaps due to minor temperature fluctuations (7). Different degrees of probe degradation are likely to be the reason for a decreased accuracy because identical reactions can yield different $\mathrm{C}_{\mathrm{T}}$ values.

The accuracy of quantifications is increased by the application of DNA polymerase without endonucleolytic activities, which does not degrade hybridization probes in LightCycler realtime quantitative PCR. Nevertheless, it might well be that, by careful optimiza- tion of the Taq DNA polymerase catalyzed reaction, similar results as with the Stoffel fragment can be obtained.

The problem of probe hydrolysis does not arise with Stoffel fragment, whose amplification efficiency is significantly more sensitive to the $\mathrm{Mg}^{2+}$ concentration than that of the Taq DNA polymerase. With less than $6 \mathrm{mM}$ $\mathrm{Mg}^{2+}$, the amplification curves for Taq DNA polymerase but in particular for Stoffel fragment become flat and the $\mathrm{C}_{\mathrm{T}}$ values higher, indicating a lower efficiency (Figure 4). On the other hand, with these high $\mathrm{Mg}^{2+}$ concentrations, the Stoffel fragment tends to form substantial amounts of nonspecific products, which is correlated with low accuracy of quantification (unpublished data). When TaqStart antibody is added before amplification, the formation of nonspecific products is completely prevented and high accuracy is achieved. At $6 \mathrm{mM} \mathrm{Mg}^{2+}$, reactions with Stoffel fragment always yielded higher amplification signal curves than obtained in corresponding experiments with Taq DNA polymerase. For both enzymes,
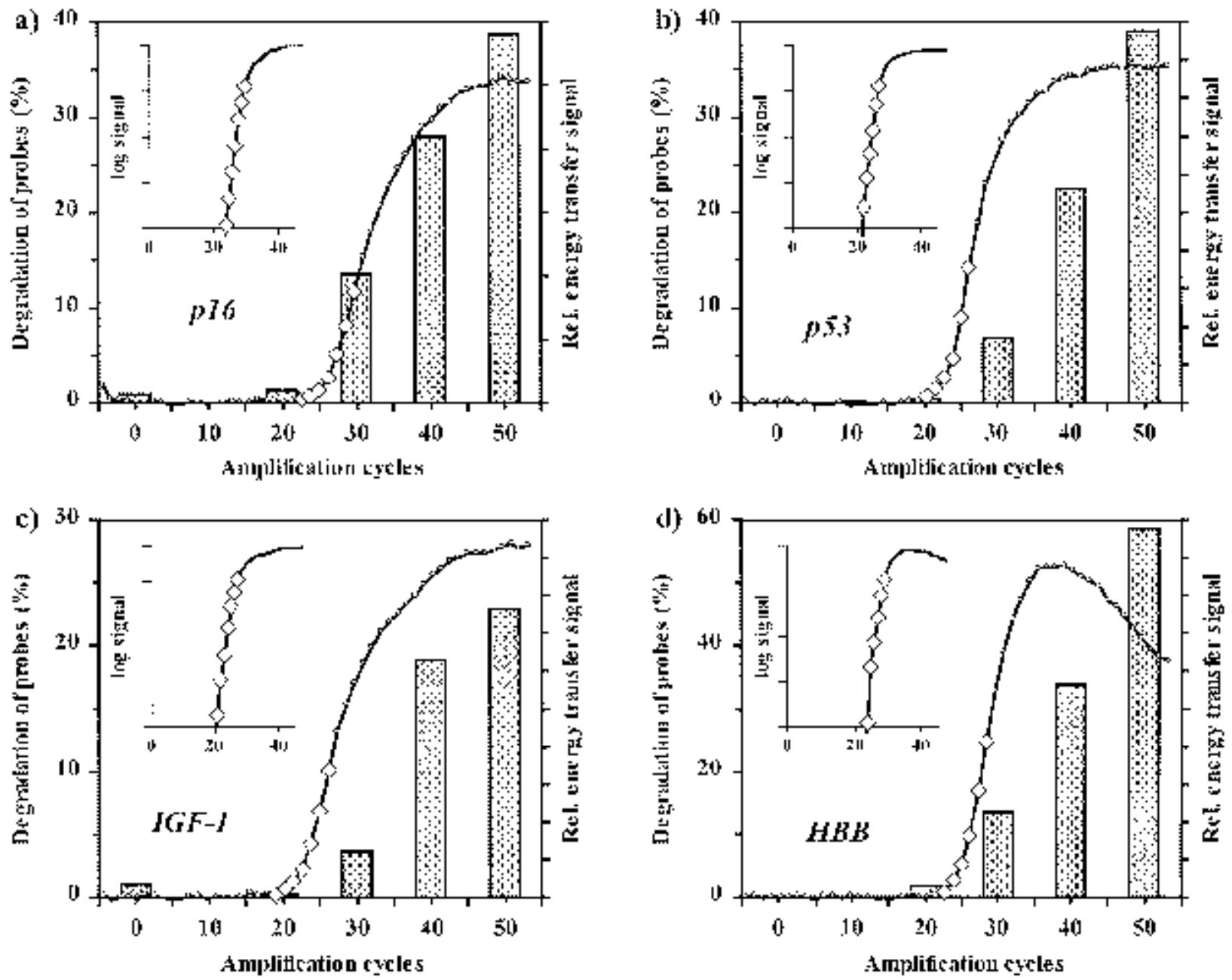

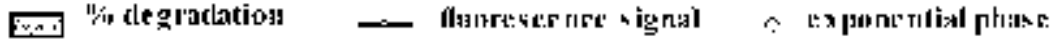

Figure 3. Accumulation of donor probe hydrolysis products during PCR. Taq DNA polymerase was used for amplification. The fractions of hydrolyzed donor probes were calculated from the peak areas of the corresponding electropherograms as described in Materials and Methods. Data points within the detectable exponential phase of each reaction are labeled with rhombic symbols. These data points are also shown in semi-logarithmic plots (see the small inserted diagrams). 


\section{Research Report}

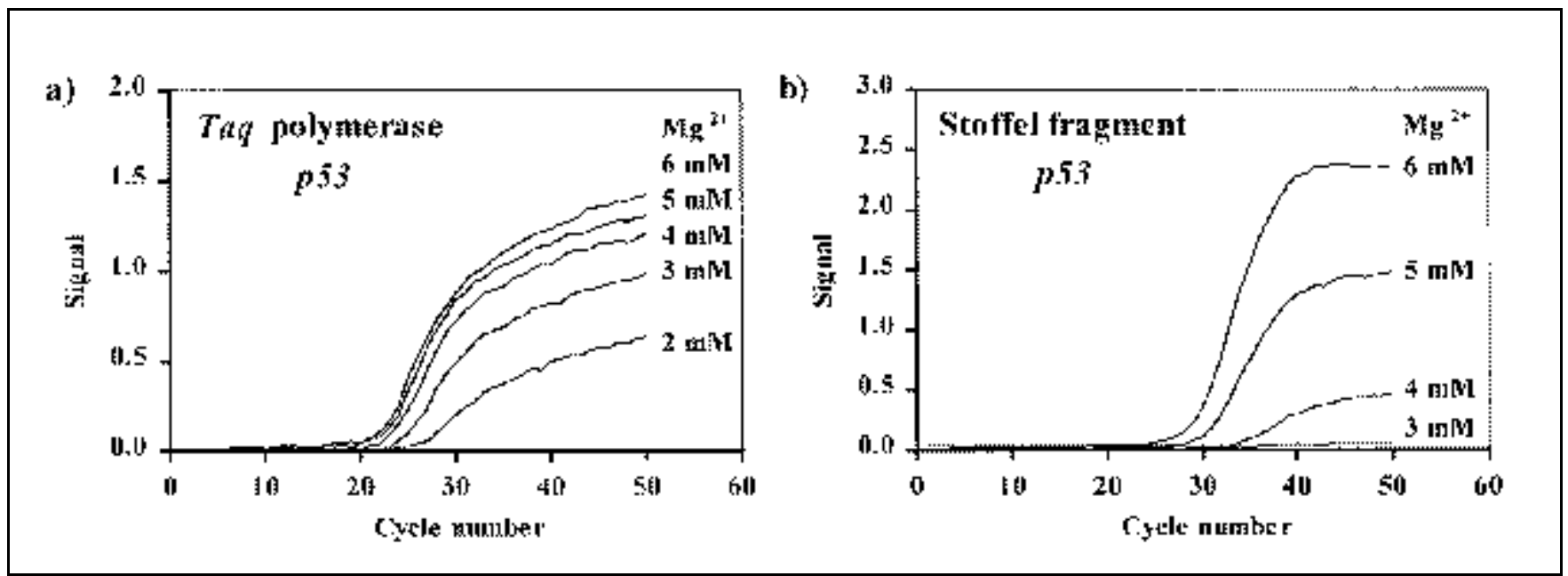

Figure 4. Dependence of cycle-dependent signal development on $\mathbf{M g}^{\mathbf{2}+}$ concentration. PCRs containing $30 \mathrm{ng}$ genomic template DNA were carried out with different $\mathrm{Mg}^{2}+$ concentrations under the same conditions. Higher $\mathrm{Mg}^{2+}$ concentrations led to an earlier increase of signal (lower $\mathrm{G}$ values), higher signals, higher signal-to-noise ratio, and a better defined segment of the exponential phase required for determination of the G values. (a) refers to Taq DNA polymerase and $p 53$, and (b) refers to Stoffel fragment and $p 53$.

the efficiencies calculated from several independent standard curves $\left(\varepsilon=10^{\frac{-1}{\mathrm{~m}}}\right.$; $\mathrm{m}$ : slope) varied between 1.84 and 1.92 . Within this range, there was no correlation between efficiencies and maximum signal intensities. These higher signal curves can be due to the absence of probe hydrolysis of the Stoffel fragment during the PCR. This results in two effects influencing the accuracy of the quantification: a higher signal yield reduces the signal-to-noise ratio and measuring points of earlier cycles can be assigned to the exponential phase of the amplification used for data evaluation. Therefore, more points can be used to calculate the $C_{T}$ values, resulting in a more robust filtering of noise. We do not imply that there is a strict causal correlation between probe hydrolysis and signal quality but that a poor signal may be due in part to probe degradation.

Generally, when using the acceptor: donor fluorescence ratio for evaluation instead of the acceptor fluorescence, more accurate results are obtained. This ratio eliminates stochastic effects that contribute similarly to the signal intensities of both fluorophores. This reduces noise and errors caused by differences in fluorophor concentrations because of pipetting errors.

The number of LighCycler users is continuously growing because this system is known to allow for the fast, but nevertheless accurate, quantifications of initial target copy numbers. Details of the assay conditions described in this paper will be useful for the analysis of very minor differences in initial copy numbers by rapid-cycle, real-time quantitative PCR.

\section{ACKNOWLEDGMENTS}

This work was supported by the Deutsche Forschungsgemeinschaft (Graduiertenkolleg Molekulare Biologie und Pharmakologie) and the Bundesministerium für Bildung, Wissenschaft, Forschung und Technologie (Fö-Kz 0311 412).

\section{REFERENCES}

1.Heid, C.A., J. Stevens, K.J. Livak, and P.M. Williams. 1996. Real time quantitative PCR. Genome Res. 6:986-994.

2.Higuchi, R., C. Fockler, G. Dollinger, and R. Watson. 1993. Kinetic PCR analysis: realtime monitoring of DNA amplification reactions. BioTechnology 11:1026-1030.

3.Lawyer, F.C., S. Stoffel, R.K. Saiki, S.Y. Chang, P.A. Landre, R.D. Abramson, and D.H. Gelfand. 1993. High-level expression, purification, and enzymatic characterization of full-length Thermus aquaticus DNA polymerase and a truncated form deficient in $5^{\prime}$ to 3' exonuclease activity. PCR Methods Appl. 2:275-287.

4.Livak, K.J., S.J. Flood, J. Marmaro, W. Giusti, and K. Deetz. 1995. Oligonucleotides with fluorescent dyes at opposite ends provide a quenched probe system useful for detecting PCR product and nucleic acid hybridisation. PCR Methods Appl. 4:357-362.
5.Lyamichev, V., M.A.D. Brow, V.E. Varvel, and J.E. Dahlberg. 1999. Comparison of the $5^{\prime}$ nuclease activities of Taq DNA polymerase and its isolated nuclease domain. Proc. Natl. Acad. Sci. USA 96:6143-6148.

6.Tyagi, S. and F.R. Kramer. 1996. Molecular beacons: probes that fluoresce upon hybridization. Nat. Biotechnol. 14:303-308.

7.Wilhelm, J., M. Hahn, and A. Pingoud. 2000. Influence of DNA target melting behavior on real-time PCR quantification. Clin. Chem. 46:1738-1743.

8.Wittwer, C.T., K.M. Ririe, R.V. Andrew, D.A. David, R.A. Gundry, and U.J. Balis. 1997. The LightCycler ${ }^{\mathrm{TM}}$ : a microvolume multisample fluorimeter with rapid temperature control. BioTechniques 22:176-181.

9.Wittwer, C.T., M.G. Herrmann, A.A. Moss, and R.P. Rasmussen. 1997. Continuous fluorescence monitoring of rapid cycle DNA am plification. BioTechniques 22:130-138.

Received 2 August 2000; accepted 18 December 2000.

\section{Address correspondence to:}

Dr. Meinhard Hahn

Institut für Biochemie

FB 08

Justus-Liebig-Universität, Giessen

Heinrich-Buff-Ring 58

D-35392 Giessen, Germany

e-mail:meinhard.u.hahn@chemie.

bio.uni-giessen.de 